\title{
Letter to the Editor: Pelleted Calf Starter with Straw Access Can Confound Results: A Comment on Bach et al. (2007)
}

\author{
A. F. Kertz \\ ANDHIL LLC, 9909 Manchester Road, \#366, St. Louis, MO 63122-1915
}

Field application of the report by Bach et al. (2007) should be done with caution based on a key condition. In the Materials and Methods section, the statement that "Calves were not offered any roughage (although it is likely that they consumed some straw from bedding)" could explain why calves were ostensibly able to eat less pelleted starter without marginal acidosis, have similar BW gain, and have increased feed efficiency compared with calves fed the multiparticle starter. Unfortunately, the amount of straw that may have been consumed is unknown. In addition, because the parenthetical acknowledgment about potential straw intake was not addressed in other sections of the paper, few readers would recognize the potential relationship and effect of straw intake on calves when fed pelleted starters. Granted, calves on both multiparticle and pelleted starters could have consumed straw, but calves fed the pelleted starter would most likely have consumed straw because they were likely to be marginally acidotic. Support for this alternative hypothesis is found in part by the following publications addressing key components of calves not having straw available for consumption while fed starters in pellet or coarse mash form (Porter et al., 2007): difficulty with calculating feed efficiency for young calves (Kertz and Chester-Jones, 2004); mar-

Received June 11, 2007.

Accepted July 30, 2007.

E-mail: andhil@swbell.net ginal acidosis and impact on rumen tissues from feeding a pelleted starter (Block and Shellenberger, 1980); widespread field observations that calves fed that commercially available pelleted starter (Block and Shellenberger, 1980) in the 1980s chewed available wood in housing facilities when roughage was not available; and confounding effects of greater rumen and gut fill on weight gain with increasing starter roughage levels (Stobo et al., 1966). Body weight gain can be especially deceptive in young calves in the absence of other growth measures such as height and length.

In full disclosure, I have done consulting work with the Rancho Las Nieves [the location for the Bach et al. (2007) study] and I have discussed and shared these thoughts with the senior author of the study, Alex Bach.

\section{REFERENCES}

Bach, A., A. Giménez, J. L. Juaristi, and J. Ahedo. 2007. Effects of physical form of a starter for dairy replacement calves on feed intake and performance. J. Dairy Sci. 90:3028-3033.

Block, E., and P. R. Shellenberger. 1980. Woodpulp fines or corn silage as roughages in complete rations or a pelleted complete ration for young dairy replacements from birth through 18 weeks of age. J. Dairy Sci. 63:2060-2070.

Kertz, A. F., and H. Chester-Jones. 2004. Guidelines for measuring and reporting calf and heifer experimental data. J. Dairy Sci. 87:3577-3580.

Porter, J. C., R. G. Warner, and A. F. Kertz. 2007. Effect of fiber level and physical form of starter on growth and development of dairy calves fed no forage. Prof. Anim. Sci. 23:395-400.

Stobo, I. J. F., J. H. B. Roy, and H. J. Gaston. 1966. Rumen development in the calf. 1 . The effect of diets containing different proportions of concentrate to hay on rumen development. Br. J. Nutr. $20: 171-191$ 